\title{
Interactive comment on "The spectral signature of cloud spatial structure in shortwave irradiance" by S. Song et al.
}

\section{S. Song et al.}

sebastian.schmidt@lasp.colorado.edu

Received and published: 12 August 2016

The comment was uploaded in the form of a supplement:

http://www.atmos-chem-phys-discuss.net/acp-2015-911/acp-2015-911-AC2-

supplement.pdf

Interactive comment on Atmos. Chem. Phys. Discuss., doi:10.5194/acp-2015-911, 2016. 